\title{
Angiopoietin-1 is expressed in the synovium of patients with rheumatoid arthritis and is induced by tumour necrosis factor $\alpha$
}

\author{
E M Gravallese, A R Pettit, R Lee, R Madore, C Manning, A Tsay, J Gaspar, \\ $M$ B Goldring, S R Goldring, P Oettgen
}

See end of article for authors' affiliations

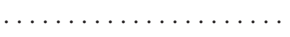

Correspondence to: Professor P Oettgen Harvard Institutes of Medicine, 4 Blackfan Circle, Boston, MA 02115 , USA; joettgen@caregroup. harvard.edu

Accepted 9 July 2002

\begin{abstract}
Objectives: To examine the potential role of the angiogenic growth factor angiopoietin-1 (Ang-1) in inflammatory arthritis.

Methods: Eighteen synovial tissue samples were obtained from 17 patients with a clinical diagnosis of rheumatoid arthritis (RA) and compared with six synovial tissue samples from six patients with osteoarthritis (OA). Ang-1 expression in synovial tissues was determined by immunohistochemistry and in situ hybridisation. Ang-1 mRNA and protein expression were also examined by northern blot analysis and enzyme linked immunosorbent assay (ELISA) in cultured synovial fibroblasts and human umbilical vein endothelial cells (HUVECs) before and after treatment with tumour necrosis factor (TNF) $\alpha$. Results: Ang-1 protein expression was detected by immunohistochemistry in 16/18 RA synovial tissue samples. Ang-1 protein was frequently observed in the synovial lining layer and in cells within the sublining synovial tissue, in both perivascular areas and in areas remote from vessels. In contrast, Ang-1 was only weakly detected in these sites in OA samples. Ang-1 mRNA and protein were also expressed in cultured synovial fibroblasts derived from patients with RA. In addition, induction of Ang-1 mRNA and protein was observed by northern blot analysis and ELISA after stimulation of RA synovial fibroblasts, but not HUVECs, with the proinflammatory cytokine TNF $\alpha$.

Conclusions: Ang-1 mRNA and protein are expressed in the synovium of patients with RA, and are up regulated in synovial fibroblasts by TNF $\alpha$. Ang-1 may therefore be an important regulator of angiogenesis in inflammatory arthritis.
\end{abstract}

A ngiogenesis has been shown to have an important role in tissue repair and in promoting the growth of new tissue in a number of inflammatory disorders such as psoriasis, rheumatoid arthritis (RA) and wound healing. ${ }^{1-3}$ The process of angiogenesis is a highly orchestrated series of events that eventually leads to the formation of new blood vessels. One of the first steps in this process is the induction of angiogenic growth factors such as basic fibroblast growth factor (bFGF) and vascular endothelial growth factor (VEGF). These growth factors promote the proliferation and migration of endothelial cells to sites of inflammation, a process that is facilitated by the expression of matrix degrading enzymes and integrins by activated endothelial cells. Endothelial cells that have migrated to sites of inflammation then organise into small tubes. The formation of stable blood vessels requires the recruitment of surrounding mesenchymal cells and their differentiation into vascular smooth muscle cells. Vessel maturation is facilitated by the recently identified angiopoietins. Angiopoietin-1 (Ang-1) has the unique property of enhancing the stability of new blood vessels by recruiting surrounding mesenchymal cells and promoting their differentiation into vascular smooth muscle cells. ${ }^{4}$ Ang-2 has been identified as a natural antagonist of Ang-1 and can inhibit angiogenesis. ${ }^{5}$ Thus, angiogenesis requires not only the active proliferation and migration of new endothelial cells to sites of inflammation but also the stabilisation of the vessel wall through the coordinated actions of the angiopoietins.

RA is a chronic systemic inflammatory disease characterised by progressive joint destruction. A major pathological feature of RA is inflammation of synovial tissues, accompanied by synovial proliferation and the formation of "pannus". Several studies have demonstrated marked neovascularisation within the inflamed synovium of patients with RA. ${ }^{67}$
Angiogenesis occurs early in the development of RA and the increase in vessel numbers is greatest near the synovial lining layer. In one study, synovial tissue samples were obtained from patients with a recent diagnosis of arthritis but whose disease was quiescent at the time of the biopsy. ${ }^{7}$ Most of the patients with RA had histological evidence of synovitis with synovial lining cell hyperplasia and lymphocyte infiltration. All these patients had increased synovial vascularity compared with patients without evidence of synovitis. Morphometric analysis of blood vessels in early RA showed an increase in the number of postcapillary venules. ${ }^{6}$ Examination of the synovial vasculature has also been performed in patients with chronic RA. ${ }^{8}$ The mean duration of the disease in these patients was 15 years. These patients exhibited a diminished capillary density within the synovium compared with normal controls. This suggests either that the treatment that these patients received resulted in a decrease in vascular density or that there was a natural regression in the number of blood vessels at later stages of the disease.

Angiogenesis has also been seen in animal models of RA, such as the collagen induced arthritis (CIA) and adjuvant induced arthritis models. ${ }^{90}$ The development of new blood

Abbreviations: Ang-1; angiopoietin-1; bFGF, basic fibroblast growth factor; CIA, collagen induced arthritis; DAB, diaminobenzidine; DMEM, Dulbecco's modified Eagle's medium; ELISA, enzyme linked immunosorbent assay; FCS, fetal calf serum; HRP, horseradish peroxidase; HUVECs, human umbilical vein endothelial cells; IL, interleukin; OA, osteoarthritis; PBS, phosphate buffered saline; RA rheumatoid arthritis; RT-PCR, reverse transcriptase-polymerase chain reaction; TBS, Tris buffered saline; TNF, tumour necrosis factor; VEGF, vascular endothelial growth factor 
vessels presumably promotes the growth of synovial tissue by increasing the supply of oxygen and nutrients to proliferating cells. ${ }^{11}$ In addition to their role in providing blood supply to the inflamed synovium in arthritis, the endothelial cells derived from new blood vessels actively participate in the inflammatory response by recruiting lymphocytes, macrophages, and other inflammatory cells, and by producing cytokines and angiogenic factors. ${ }^{2}$

Several angiogenic growth factors are expressed within the rheumatoid synovium, including VEGF, bFGF, hepatocyte growth factor, and transforming growth factor $\beta \cdot{ }^{12-17}$ Stimuli for the local release of angiogenic substances such as VEGF and bFGF include hypoxia and the proinflammatory cytokines tumour necrosis factor (TNF) $\alpha$ and interleukin (IL) $1 \beta .^{211}$ These angiogenic factors act to promote the proliferation and migration of endothelial cells. Because Ang-l is a critical mediator of the later stages of blood vessel development and vessel maturation, we would expect that expression of Ang-1 might also be required for the angiogenic response associated with inflammatory diseases such as RA. The specific goal of this study was to examine the potential role of Ang-l as a mediator of the angiogenesis associated with RA.

\section{METHODS}

\section{Tissue culture and reagents}

Synovial tissue and bone were obtained at the time of arthroplasty or joint replacement surgery from patients with the clinical diagnosis of RA or osteoarthritis (OA). Tissue procurement was approved by the Institutional Review Board. Dispersed synovial tissues were prepared by a previously published method. ${ }^{18}$ Briefly, synovial tissues were minced on tissue culture plates and treated with type I collagenase (4 $\mathrm{mg} / \mathrm{ml}$; Worthington Biochemical Corporation, Lakewood, NJ) in Dulbecco's modified Eagle's medium (DMEM, Gibco BRL), incubated for one hour at $37^{\circ} \mathrm{C}$, treated with $0.25 \%$ trypsin for 30 minutes, harvested, and centrifuged at $1000 \mathrm{rpm}$ for 10 minutes. Pellets were suspended in $0.05 \%$ trypsin- $0.02 \%$ EDTA, centrifuged, and resuspended in 50\% phosphate buffered saline (PBS, $\mathrm{Ca}^{2+} / \mathrm{Mg}^{2+}$ free), 50\% DMEM containing $10 \%$ fetal calf serum (FCS; Sigma, St Louis, MO). Cells were then centrifuged and suspended in DMEM, 10\% FCS, and plated at a density of $10 \times 10^{6}$ cells $/ 10 \mathrm{~cm}$ plate. Cells were initially grown for 7-10 days and subsequently subjected to two to four passages. Primary human umbilical vein endothelial cells (HUVECs) were purchased from Cambrex Biosciences (Walkersville, MD) and cultured as recommended. TNF $\alpha$ and ILl $\beta$ were purchased from NIBSC (United Kingdom) and from Research Diagnostics Inc (Flanders, NJ).

\section{RNA and northern blot analysis}

Northern blots were generated with RNA derived from cultured synovial fibroblasts of three patients with RA and from cultured HUVECs. Total RNA was extracted from the cells using the Trizol reagent (Gibco BRL) according to the manufacturer's protocol. Total RNA $(10 \mu \mathrm{g})$ was loaded in each lane on a formaldehyde denaturing gel, and RNA was transferred to MagnaCharge membrane (Osmonics, Minnetonka, MN) by capillary transfer. Probes for northern blot analysis and in situ hybridisation were as follows: a $560 \mathrm{bp}$ Ang-1-specific cDNA fragment was isolated by reverse transcriptase-polymerase chain reaction (RT-PCR) from human placental RNA (BD Biosciences Clontech, Palo Alto, CA) and subcloned into the pCRII vector (Invitrogen) for the preparation of riboprobes for in situ hybridisation. Ang-1specific primers used to generate this fragment were 5'-AGAACTAGTTTTAGAGGTCAGAAG-3' and 5'-CAGCAG CTGTATCTCAAGTCG-3'. A 582 bp Ang-2-specific cDNA fragment was similarly isolated from human placenta using the following primers: 5'-AGAGAGGAACAAAGGACCGTG-3' and $5^{\prime}$-TCAAGCTTCATTAGCCACTGAG-3'. The entire sequence of each subcloned fragment was verified by DNA sequencing using the Applied Biosciences 377 DNA sequencer. The cDNA inserts were isolated by appropriate enzymatic digestion and labelled with $\alpha-{ }^{32} \mathrm{P}$-CTP (New England Nuclear, Boston, MA) using a Ready-to-Go cDNA labelling kit (Pharmacia, Piscataway, NJ) for probes in northern blot analysis. Blots were hybridised in Ultrahyb (Ambion, Austin, TX).

\section{Immunohistochemistry}

RA synovial soft tissue and bone were fixed for 24-48 hours in $4 \%$ paraformaldehyde and specimens containing bone were subsequently decalcified for at least two weeks in 14\% EDTA. Specimens were processed for paraffin embedding (Citadel 1000, Shandon, Pittsburgh, USA) and 4 or $5 \mu \mathrm{m}$ serial sections were cut for immunohistochemical staining using an immunoperoxidase technique with diaminobenzidine (DAB, Dako, Carpinteria, CA) as the chromogen. Briefly, sections were deparaffinised followed by microwave antigen retrieval (GE Sensor convection microwave oven), in $10 \mathrm{mM}$ EDTA pH 7.5 at $93^{\circ} \mathrm{C}$ for 10 minutes and allowed to cool for at least two hours. Sections were washed in Tris buffered saline (TBS) and incubated for 60 minutes in serum block (10\% FCS and 10\% normal swine serum or $10 \%$ normal rabbit serum diluted in TBS). Sections were then incubated with an affinity purified rabbit polyclonal antihuman Ang-l antibody (L41309M, Regeneron Pharmaceuticals Inc, Tarrytown, NY), mouse antihuman CD68 antibody (PM-Gl, Dako), or with the appropriate isotype matched control antibody (polyclonal rabbit IgG, Santa Cruz Biotechnology Inc, Santa Cruz, CA, or mouse IgG3א, BD Pharmingen, San Diego, CA) for 60 minutes. All incubations were carried out at room temperature. Sections were washed between every subsequent step with TBS. Endogenous peroxidase activity was blocked by incubating the sections in $3 \% \mathrm{H}_{2} \mathrm{O}_{2}$ (diluted in TBS) for 30 minutes. Sections were subsequently incubated for 30 minutes with a biotinylated $\mathrm{F}\left(\mathrm{ab}^{\prime}\right)_{2}$, fragment of swine antirabbit or rabbit antimouse immunoglobulin (Dako), followed by horseradish peroxidase (HRP) conjugated streptavidin (Dako), and developed with DAB (Dako) chromogen to the manufacturer's specifications. The sections were counterstained with haematoxylin (Sigma Diagnostics, St Louis, USA). Slides were examined and photographed using a transmitted light microscope and camera (Nikon, Tokyo, Japan).

\section{In situ hybridisation}

Fixed and decalcified tissues, in cases where bone was present, were processed for paraffin embedding. Paraffin sections $(5 \mu \mathrm{m})$ were placed on poly-L-lysine coated slides, dried overnight, and used immediately or stored at $4^{\circ} \mathrm{C}$. Preparation of probes, prehybridisation, and hybridisation were performed according to a modification of previously published methods. ${ }^{19}$ In brief, slides were deparaffinised in xylenes and rehydrated through graded ethanol solutions. Prehybridisation included digestion with proteinase $\mathrm{K}(20 \mu \mathrm{g} / \mathrm{ml})$ in PBS (eight minutes at $\left.37^{\circ} \mathrm{C}\right)$, followed by fixation in $4 \%$ paraformaldehyde ( 10 minutes) and acetylation in $0.25 \%$ acetic anhydride in $100 \mathrm{mM}$ triethanolamine. Hybridisation was performed overnight at $45-50^{\circ} \mathrm{C}$. The hybridisation solution contained 50\% formamide, $0.3 \mathrm{M} \mathrm{NaCl}$, $20 \mathrm{mM}$ Tris- $\mathrm{HCl}$ (pH 7.5), $5 \mathrm{mM}$ EDTA, $10 \mathrm{mM} \mathrm{NaH} \mathrm{PO}_{4}(\mathrm{pH}$ 8.0 ), $10 \%$ dextran sulphate, $1 \times$ Denhardt's solution, $0.5 \mathrm{mg} / \mathrm{ml}$ total yeast RNA, and $0.1 \mathrm{M}$ dithiothreitol. The pCRII vectors containing the subcloned Ang-1 and Ang-2 cDNA fragments were used to generate riboprobes for in situ hybridisation. $\mathrm{A}^{33} \mathrm{P}$ radiolabelled probe was added $\left(5 \times 10^{4} \mathrm{cpm} / \mu \mathrm{l}\right)$ in a volume of 40 $\mu \mathrm{l} /$ slide. Washes were in graded saline-sodium citrate solutions and included treatment with RNase A (Pharmacia Biotech, Piscataway, $\mathrm{NJ}$ ) at $37^{\circ} \mathrm{C}$ for $1.5-2$ hours. Air dried slides were dipped in Kodak NTB-2 emulsion (Eastman Kodak, Rochester, $\mathrm{NY}$ ), drained, air dried for one hour, and placed in a light-proof container with desiccant at $4^{\circ} \mathrm{C}$ for $7-10$ weeks. Slides were 

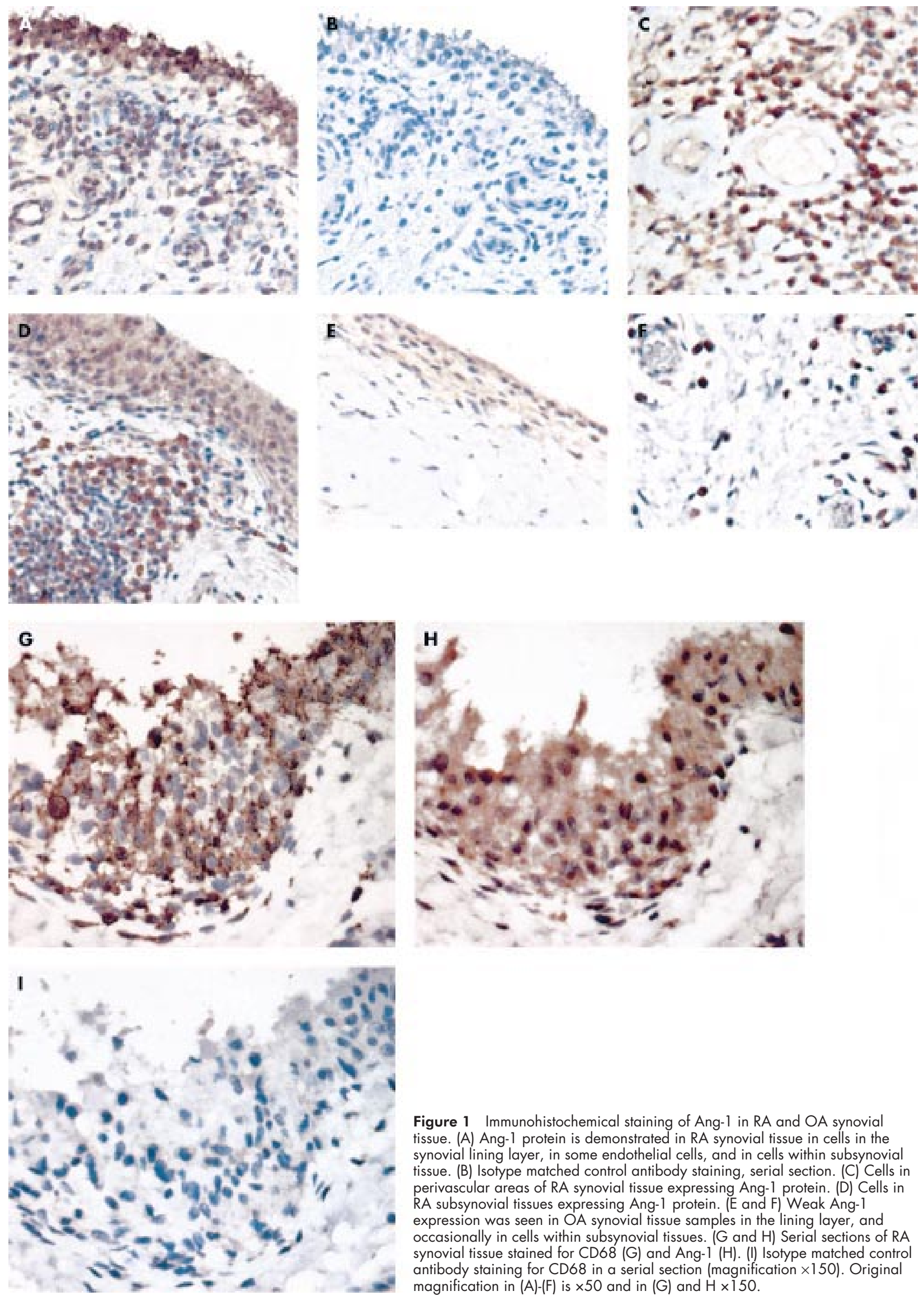

Figure 1 Immunohistochemical staining of Ang-1 in RA and OA synovial tissue. (A) Ang-1 protein is demonstrated in RA synovial tissue in cells in the synovial lining layer, in some endothelial cells, and in cells within subsynovial tissue. (B) Isotype matched control antibody staining, serial section. (C) Cells in perivascular areas of RA synovial tissue expressing Ang-1 protein. (D) Cells in RA subsynovial tissues expressing Ang- 1 protein. (E and F) Weak Ang-1 expression was seen in OA synovial tissue samples in the lining layer, and occasionally in cells within subsynovial tissues. ( $G$ and $H$ ) Serial sections of RA synovial tissue stained for CD68 (G) and Ang-1 (H). (I) Isotype matched control antibody staining for $\mathrm{CD} 68$ in a serial section (magnification $\times 150$ ). Original magnification in $(A)-(F)$ is $\times 50$ and in $(G)$ and $\mathrm{H} \times 150$. 

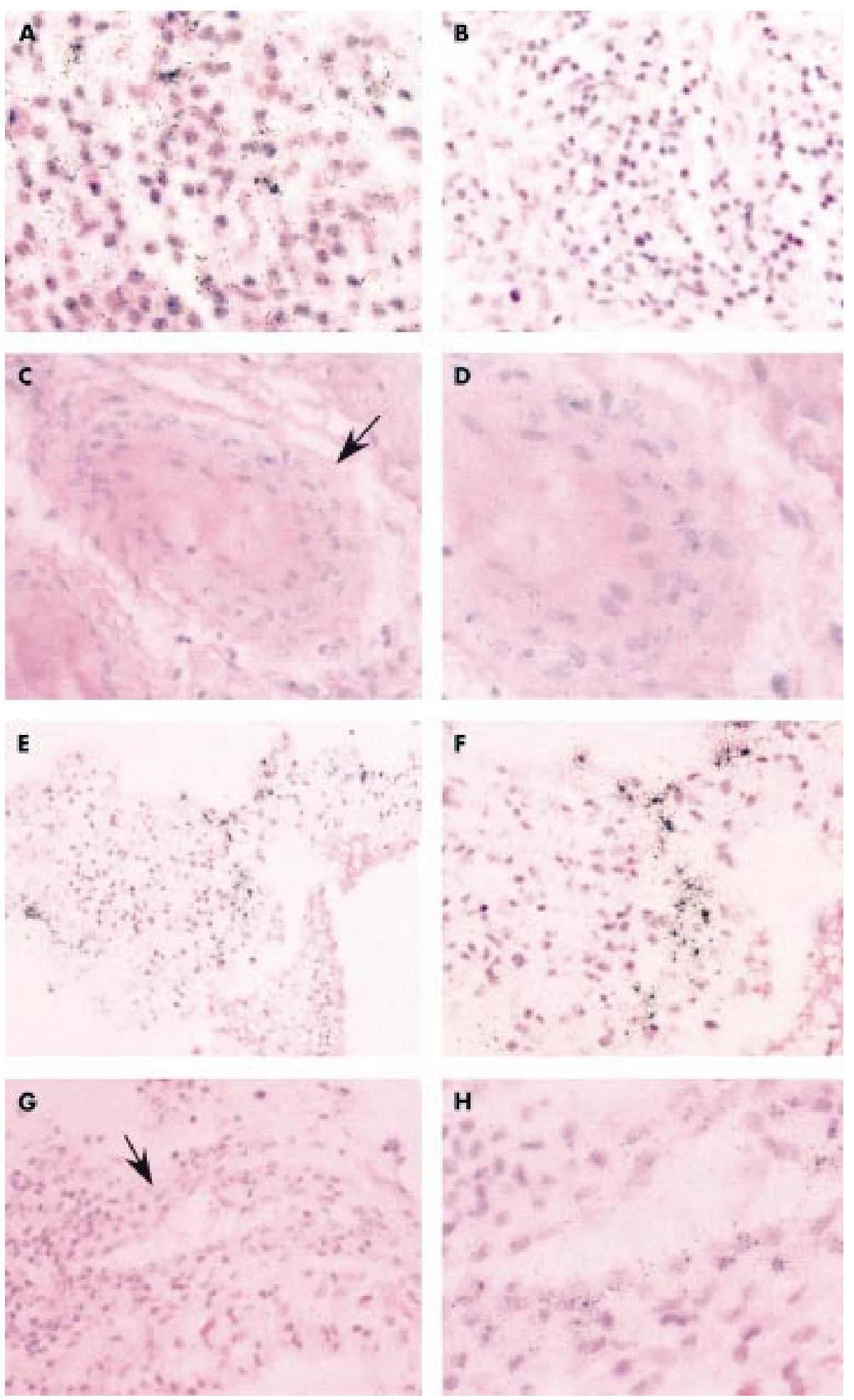

Figure 2 In situ hybridisation for Ang-1 and Ang-2 in rheumatoid synovium. Ang-1 in situ hybridisation in synovial tissue samples from patients with RA using the Ang-1 antisense (A, C-F) and sense (B) probes, demonstrating representative areas of mRNA expression for Ang-1. Probe hybridisation is noted in isolated cells within the subsynovial tissues (A), and within cells in the wall of a subsynovial arteriole (C, arrow), shown at higher magnification (D). (E and F) Low and high power views of Ang-1 hybridisation within cells of the synovial lining layer seen in two samples. In situ hybridisation using the Ang-2 antisense probe demonstrating probe hybridisation within a subsynovial vessel at low (G, arrow) and high power magnification $(H)$. Original magnification in $(A),(B)$, and $(E-G)$ is $\times 50$ and in $(C)$, (D), and $(H) \times 150$.

developed in Kodak D-19 developer, fixed in Kodak fixer, and counterstained with haematoxylin and eosin.

\section{Enzyme linked immunosorbent assay (ELISA)}

ELISA studies were performed at Regeneron Pharmaceuticals Inc. Ang- 1 and Ang-2 protein concentrations in culture media derived from cultured RA synovial fibroblasts from two patients and synovial fibroblast cell extracts from one patient were measured by ELISA using recombinant Tie2 to capture, and an N-terminal antibody against Ang-1 or Ang-2 to report. Briefly, CHO-derived rat Tie2 ectodomain coupled to human Fc (Tie2Fc, $3 \mu \mathrm{g} / \mathrm{ml}$ ) was coated on 96 well Immobilin plates. 
The plates were washed and blocked with $0.2 \%$ I-block (Tropix, Foster City, CA) and 0.1\% Tween 20. Serial dilutions of culture media or cell extracts were added to the wells for two hours at room temperature, alongside a standard curve of known amounts of Ang-1 in 6.6\% bovine serum albumin buffer. Ang-1 or Ang-2 concentrations were then reported by adding a rabbit polyclonal antibody raised against the $\mathrm{N}$-terminus of either Ang-1 or Ang-2 (225 and $270 \mathrm{ng} / \mathrm{ml}$, respectively) for one hour at room temperature. All experiments were performed in triplicate. Bound antibody was visualised using goat antirabbit IgG linked to HRP ( $100 \mathrm{ng} / \mathrm{ml}$, Vector Laboratories Inc, Burlingame, CA) for one hour followed by tetramethylbenzidine substrate (Vector). Substrate was developed for 30 minutes, stopped with $2 \mathrm{~N}$ sulphuric acid and read at $450-570 \mathrm{~nm}$ in a spectrophotometer (Molecular Devices, Cupertino, CA).

\section{RESULTS}

Expression of Ang-1 protein in synovial tissues from patients with RA and OA

The role of the angiopoietins in promoting angiogenesis in RA has not been studied extensively. Unlike the other angiogenic substances detected thus far in RA, the angiopoietins are critical mediators of the later stages of blood vessel development. We therefore speculated that they might also be necessary for the angiogenic response in RA. To examine this possibility, synovial tissues were obtained from patients with a clinical diagnosis of RA or OA. Eighteen RA synovial tissue samples from 17 patients who were undergoing arthroplasty or joint replacement surgery were examined for Ang-1 protein expression by immunohistochemistry. Ang-1 protein expression was detected in 16/18 samples. Ang-1 protein was frequently observed in the synovial lining layer and in the sublining synovial tissue in cells located in perivascular areas, in areas remote from vessels, and occasionally in endothelial cells (figs $\mathrm{lA}, \mathrm{C}$, and D). Positive staining was determined by comparison with a serial section incubated with an isotype matched control antibody (fig 1B). Staining of serial sections with anti-CD68 (fig 1G) and anti-Ang-1 (fig 1H) antibodies showed that both macrophage-like and fibroblast-like synovial lining layer cells expressed Ang-l protein. Specificity of CD68 staining was determined by comparison with isotype matched control antibody staining in a serial section (fig II). Ang-1 protein expression was also demonstrated in the six OA samples studied. However, the number of cells expressing Ang- 1 in these samples was generally lower than that seen in RA, and when compared in the same immunohistochemistry experiment, the level of Ang-1 expression in the synovial lining layer was generally lower in OA than RA samples (fig $1 E$ ). The pattern of Ang- 1 expression in OA samples was similar to that seen in RA tissues, including expression in synovial lining layer cells and occasional sublining cells in perivascular areas (figs $\mathrm{IE}$ and $\mathrm{F}$ ).

\section{In situ hybridisation of Ang-1 and Ang-2 mRNA in synovial tissues from patients with RA}

To examine the expression and localisation of Ang-1 mRNA in rheumatoid synovium we also performed in situ hybridisation in eight of the synovial tissue samples studied by immunohistochemistry. Three sites of Ang-l mRNA expression were identified (fig 2). Ang-1 mRNA was predominantly seen in isolated cells within sublining synovial tissue remote from vessels (fig 2A) and in cells surrounding and occasionally within small blood vessels (figs 2C and D). Ang-1 mRNA was also noted in the synovial lining layer in two samples (figs $2 \mathrm{E}$ and F). In serial tissue sections of these samples, Ang-1 expressing cells also expressed stromelysin-1 mRNA, which is a reliable marker of synovial lining cells in RA (data not shown). Probe hybridisation was not detected when the control sense probe for Ang-1 was used (fig 2B). In contrast,
A

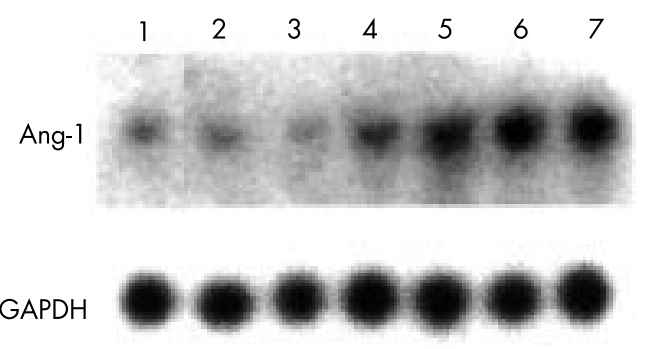

B

Ang-1

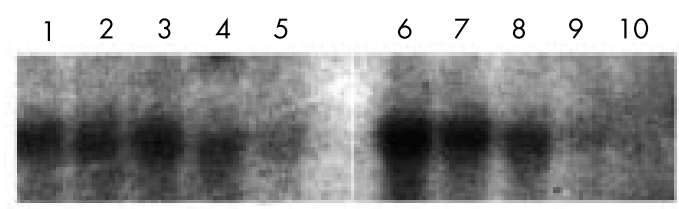

GAPDH
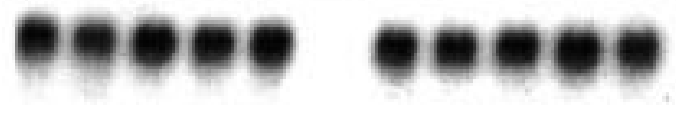

C

Ang-2
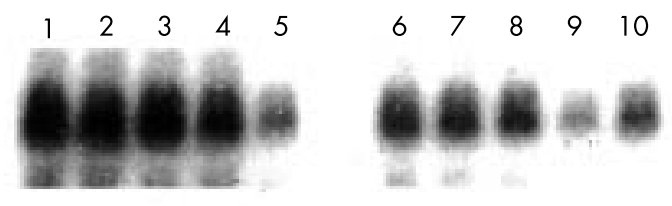

GAPDH
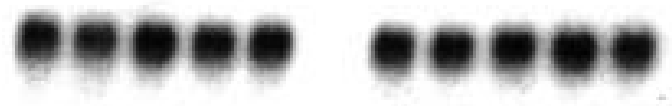

Figure 3 Northern blot analysis of Ang-1 and Ang-2 in cultured synovial fibroblasts and human umbilical endothelial cells. (A) Induction of Ang-1 mRNA expression in cultured human synovial fibroblasts in response to TNF $\alpha(10 \mathrm{ng} / \mathrm{ml})$ at baseline (lane 1) and $1,2,4,6,12$, and 24 hours after stimulation with TNF $\alpha$ lanes 2-7). (B) Repression of Ang-1 mRNA expression in cultured human umbilical vein endothelial cells in response to $I L 1 \beta(10 \mathrm{ng} / \mathrm{ml})$ and

$\mathrm{TNF} \alpha(10 \mathrm{ng} / \mathrm{ml})$ at baseline (lanes 1,6$)$ and $2,4,6$, and 24 hours after stimulation with IL $1 \beta$ (lanes 2-5) and TNF $\alpha$ (lanes 7-10). (C) Repression of Ang-2 mRNA expression in cultured human umbilical vein endothelial cells in response to IL $1 \beta(10 \mathrm{ng} / \mathrm{ml})$ and TNF $\alpha(10$ $\mathrm{ng} / \mathrm{ml}$ ) at baseline (lanes 1, 6) and 2, 4, 6, and 24 hours after stimulation with IL $1 \beta$ (lanes 2-5) and TNF $\alpha$ (lanes 7-10).

Ang-2 mRNA was predominantly seen in endothelial and/or vessel wall cells of small blood vessels including arterioles and veins in the sublining synovial tissue (figs $2 \mathrm{G}$ and $\mathrm{H}$ ) and in the synovial lining layer in one case. Probe hybridisation was not detected when the control sense probe for Ang-2 was used (data not shown).

\section{Basal Ang-1 and Ang-2 expression and response to} proinflammatory cytokines

To further examine the expression of Ang-1 and Ang-2, northern blot analysis was performed using RNA derived from cultured human synovial fibroblasts and endothelial cells. Proinflammatory cytokines have been shown to enhance the expression of other angiogenic factors in synovial cells. We therefore examined the effect of TNF $\alpha$ on the expression of angiopoietins in these cells. As shown in a representative northern blot (fig 3A), Ang-1 expression could be detected at low levels in synovial fibroblasts at third passage. Stimulation of these cells with TNF $\alpha$ led to a marked time dependent induction of Ang-1 mRNA expression from six to 24 hours. 


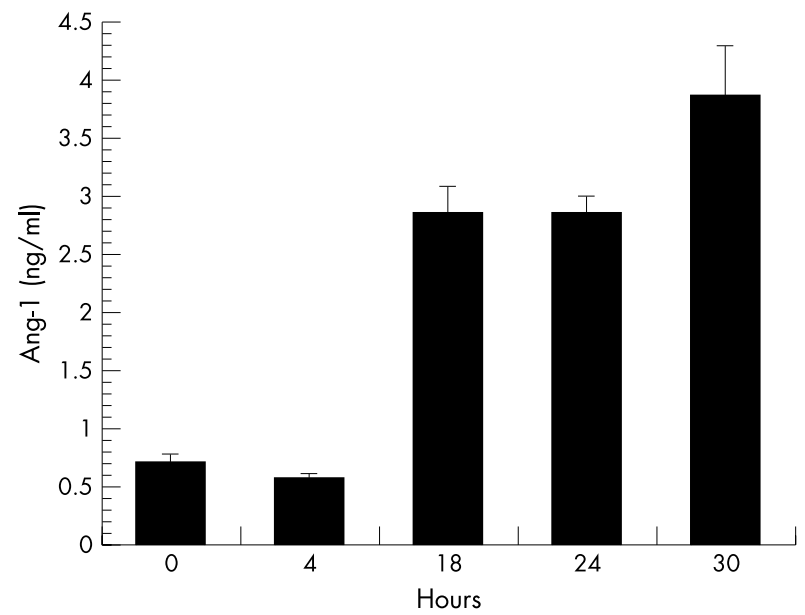

Figure 4 ELISA analysis of Ang-1 protein in culture media of RA synovial fibroblasts. Ang-1 protein was quantified in the culture media of synovial fibroblasts stimulated with TNF $\alpha(10 \mathrm{ng} / \mathrm{ml})$ at 0 , $4,18,24$, and 30 hours in this representative experiment. Experiments were performed in triplicate and are expressed as means (standard deviation).

The effect of IL1 $\beta$ stimulation was also evaluated. IL1 $\beta$ did not lead to a consistent induction of Ang-1 (data not shown). In contrast, in endothelial cells Ang-1 levels were markedly down regulated in response to ILI $\beta$, an effect that was also seen with $\mathrm{TNF} \alpha$ (fig 3B). In endothelial cells, exposure to proinflammatory cytokines also led to a decrease in Ang-2 expression that occurred between six and 24 hours (fig 3C). In contrast, Ang-2 was not detected by northern blot analysis in cultured synovial fibroblasts at baseline or in response to proinflammatory cytokines (data not shown).

To examine Ang-l protein expression by synovial fibroblasts, culture media were examined by an ELISA, because the angiopoietins are secreted proteins. Synovial fibroblasts secreted low levels of Ang-1 protein at baseline. In a representative experiment (fig 4), stimulation of the synovial fibroblasts with TNF $\alpha$ resulted in a three- to fourfold increase in the levels of Ang- 1 at 18 and 24 hours and a further increase to five- to sixfold by 30 hours. Ang-1 protein was also detected in a synovial cell lysate in one case before stimulation $(0.73$ $\mathrm{ng} / \mathrm{ml}$ ) and similarly increased in response to TNF $\alpha$ stimulation by $34 \%$ at four hours $(0.98 \mathrm{ng} / \mathrm{ml})$ and $52 \%$ at 30 hours $(1.11 \mathrm{ng} / \mathrm{ml})$. The time dependent increase in protein levels after stimulation with TNF $\alpha$ suggests that Ang- 1 is secreted from the cells and remains stable and detectable in the culture media. In contrast, no Ang-2 protein was detected by ELISA at baseline or in response to proinflammatory cytokines in the cultured synovial fibroblasts (data not shown).

\section{DISCUSSION}

Angiogenesis is a multistep process requiring the proliferation and migration of endothelial cells and the formation of primitive vascular tubes early in the process. The angiogenic factors VEGF and bFGF are mediators of the earlier stages of blood vessel development. In contrast, Ang-1 is critical for blood vessel stabilisation and maturation that requires the recruitment of surrounding mesenchymal cells and their differentiation into vascular smooth muscle cells. The goal of this study was to examine the potential role of the angiopoietins in mediating angiogenesis in RA.

The results of our study demonstrate that Ang-1 protein is expressed in the synovial lining layer and in cells within the subsynovium of patients with RA, and, to a lesser extent, in patients with OA. Furthermore, Ang-1 protein and mRNA are also expressed at low levels in cultured RA synovial fibroblasts and are markedly induced in response to TNF $\alpha$. The expression of Ang-1 mRNA in synovial tissues and cultured synovial fibroblasts obtained from patients with RA was also examined recently by quantitative RT-PCR. ${ }^{20}$ The results of this study show that Ang-l mRNA levels are raised in the synovium of patients with RA compared with normal subjects and are increased in cultured RA synovial fibroblasts compared with fibroblasts obtained from normal synovial biopsies. Stimulation of cultured RA synovial fibroblasts with TNF $\alpha$ resulted in further induction of Ang-1 mRNA expression. Our study provides independent confirmation of Ang-1 expression at the mRNA level in the synovium of patients with RA by in situ hybridisation, and in cultured RA synovial fibroblasts by northern blot analysis. Up regulation of Ang-l mRNA in response to TNF $\alpha$ was also seen in our study by northern blot analysis, and induction of Ang-1 protein was observed by ELISA. In another recent study, Ang-1 mRNA was also detected in synovial tissues from patients with RA by RT-PCR, but not in cultured RA synovial fibroblasts. ${ }^{21}$ These fibroblasts were grown similarly in $10 \%$ serum but were examined at a later passage than those in our study. It has been shown previously that synovial fibroblasts freshly isolated from the rheumatoid joint gradually lose some of their phenotypic characteristics in culture over time, including changes in proliferative ability and in expression of selected matrix metalloproteinases and adhesion molecules. ${ }^{22-24}$ The change in the phenotype of these cells after multiple passages may account for differences in the Ang-l mRNA levels observed in this previous study compared with the results reported here.

Our study further demonstrates Ang-1 protein and mRNA expression, as detected by in situ hybridisation, in cells surrounding blood vessels and in cells within relatively avascular regions of the subsynovium in patients with RA. Ang- 1 is also expressed at lower levels and in fewer cells in patients with OA in a similar distribution. The angiogenic factors VEGF and hepatocyte growth factor are also strongly expressed in the synovium of patients with RA and exhibit a weaker, more patchy distribution of expression in patients with OA. ${ }^{13} 1617$ The immunohistochemistry findings of Ang-1 expression reported here are in general agreement with one recently published report demonstrating Ang-1 protein expression in RA and OA synovial tissues using a different panel of antibodies. ${ }^{21}$ However, in our study, Ang-1 protein was often seen in the synovial lining layer. Furthermore, colocalisation experiments in serial sections demonstrate that both macrophage-like and fibroblast-like synovial lining cells are sources of Ang-1. In contrast, we showed by in situ hybridisation that Ang-2 expression was predominantly limited to cells within blood vessel walls, including endothelial cells.

Unlike other angiogenic factors, Ang- 1 is not a potent mitogen for endothelial growth. Ang- 1 is, however, a potent chemoattractant that can enhance endothelial migration. ${ }^{27}$ Other properties of Ang-1 include its ability to promote the adhesion of endothelial cells to fibronectin and to prevent endothelial cell death by inhibiting apoptosis. ${ }^{28}{ }^{29}$ Overexpression of Ang-l in transgenic mice leads to an increased number of blood vessels, demonstrating a proangiogenic effect. ${ }^{30}$ Our results show that Ang-1 is expressed in areas surrounding blood vessels and in relatively avascular regions of RA synovium, suggesting that this factor may be important not only for vessel maturation but also for the recruitment of endothelial cells. The ability of proinflammatory cytokines to down regulate the expression of Ang-1 in endothelial cells may promote their migration towards other cell types expressing Ang-1 within the RA synovium by increasing the chemotactic gradient. A reduction in Ang-1 expression in endothelial cells could occur either through endothelialspecific changes in the expression of transcription factors 
involved in regulating Ang-1, or through endothelial-specific changes in RNA stability.

Several recent studies in animals have demonstrated the potential therapeutic promise of inhibiting angiogenesis in RA. The fumagillin analogue AGM-1470, which has been shown to block angiogenesis in tumours, was used in a model of CIA in the rat. In this study, AGM-1470 was given either before or after the onset of arthritis. The administration of AGM-1470 after immunisation with collagen, but before the onset of arthritis, markedly diminished the incidence of arthritis as determined by a clinical arthritis index and radiographic assessment of joint space narrowing and bone destruction. ${ }^{10}$ Histological evidence of neovascularisation was also significantly blocked. When the agent was given after the onset of arthritis there was also a significant reduction in the clinical and radiographic indexes of arthritis after about eight days of administration, suggesting that inhibition of angiogenesis is a useful target of treatment even after the onset of disease. In a second study, cyclic RGD peptides were used to block the integrin $\alpha v \beta 3$, which is activated during angiogenesis and is also expressed on osteoclasts, an important cell type in the process of bone resorption..$^{31}$ Administration of these peptides to rabbits with adjuvant induced arthritis resulted in significant reductions in the degree of inflammation, pannus formation, and cartilage erosions, compared with control mice.$^{31}$ However, administration of the RGD peptides resulted in only a 50\% reduction in new blood vessel formation, suggesting that inhibition of angiogenesis may not be completely blocked by targeting one aspect of blood vessel development. In another recent trial in the CIA mouse model, a soluble form of the VEGF receptor was used to block angiogenesis. This led to a significant reduction in the clinical degree of arthritis as measured by clinical score and paw swelling, and a reduction of bone and cartilage destruction. ${ }^{32}$ Histological evaluation of changes in neovascularisation as a result of treatment were not examined in this study.

Our results confirm that Ang-1 mRNA and protein are expressed in the synovium of patients with RA, suggesting that Ang-1 may be an important regulator of the angiogenic response in RA, and demonstrate the pattern of Ang-1 and Ang-2 mRNA expression by in situ hybridisation. Furthermore, our studies show that Ang-1 mRNA and protein are induced in synovial fibroblasts by TNF $\alpha$, a potent mediator of inflammation in RA. Ang-1 promotes several stages of angiogenesis, including endothelial cell migration, adhesion, and vessel stabilisation, and may therefore be a particularly good target for blocking angiogenesis. Thus far, approaches to blocking angiogenesis in RA have not resulted in complete inhibition of angiogenesis or disease, and agents that block the angiopoietins have not been tested in RA. A more complete strategy to block angiogenesis in RA may be to inhibit factors important for both the early and late events in blood vessel maturation, including Ang-1, thereby targeting multiple steps in the angiogenic process.

\section{ACKNOWLEDGEMENTS}

We acknowledge the generous assistance of Donna Hylton and John Rudge at Regeneron Pharmaceuticals in performing the ELISAs. This research was supported by NIH grant R01-HL63008 (PO), by an Arthritis Foundation Biomedical Sciences Grant (EMG) and Postdoctoral Fellowship Award (ARP), and by the National Health and Medical Research Council C J Martin Fellowship (ARP).

\section{Authors' affiliations}

E M Gravallese, A R Pettit, R Lee, R Madore, C Manning, A Tsay, J Gaspar, M B Goldring, S R Goldring, P Oettgen, Beth Israel Deaconess Medical Center, Department of Medicine, New England Baptist Bone and Joint Institute, Harvard Institutes of Medicine, 4 Blackfan Circle, Boston, MA 02115 , USA

\section{REFERENCES}

1 Jackson JR, Seed MP, Kircher CH, Willoughby DA, Winkler JD. The codependence of angiogenesis and chronic inflammation. FASEB J 1997; 1 1:457-65.

2 Koch AE. Review: angiogenesis: implications for rheumatoid arthritis. Arthritis Rheum 1998;41:951-62.

3 Walsh DA. Angiogenesis and arthritis. Rheumatology (Oxford) 1999;38:103-12.

4 Suri C, Jones PF, Patan S, Bartunkova S, Maisonpierre PC, Davis S, et al. Requisite role of angiopoietin-1, a ligand for the TIE2 receptor, during embryonic angiogenesis. Cell 1996;87:1171-80

5 Maisonpierre PC, Suri C, Jones PF, Bartunkova S, Wiegand SJ, Radziejewski C, et al. Angiopoietin-2, a natural antagonist for Tie2 that disrupts in vivo angiogenesis. Science 1997;277:55-60.

6 FitzGerald O, Soden M, Yanni G, Robinson R, Bresnihan B. Morphometric analysis of blood vessels in synovial membranes obtained from clinically affected and unaffected knee joints of patients with rheumatoid arthritis. Ann Rheum Dis 1991:50:792-6.

7 Pando JA, Duray P, Yarboro C, Gourley MF, Klippel JH, Schumacher $H R$. Synovitis occurs in some clinically normal and asymptomatic joints in patients with early arthritis. J Rheumatol 2000;27:1848-54.

8 Stevens CR, Blake DR, Merry P, Revell PA, Levick JR. A comparative study by morphometry of the microvasculature in normal and rheumatoid synovium [see comments]. Arthritis Rheum 1991;34:1508-13.

9 Cleland LG. Animal models of rheumatoid arthritis [editorial]. $\mathrm{Br}$ J Rheumatol 1996;35:1041-2

10 Peacock DJ, Banquerigo ML, Brahn E. Angiogenesis inhibition suppresses collagen arthritis. J Exp Med 1992;175:1135-8.

11 Walsh DA, Wade M, Mapp PI, Blake DR. Focally regulated endothelial proliferation and cell death in human synovium. Am J Pathol 1998;152:691-702.

12 Qu Z, Huang XN, Ahmadi P, Andresevic J, Planck SR, Hart CE, et al. Expression of basic fibroblast growth factor in synovial tissue from patients with rheumatoid arthritis and degenerative joint disease. Lab lnvest 1995;73:339-46.

13 Fava RA, Olsen NJ, Spencer-Green G, Yeo KT, Yeo TK, Berse B, et al. Vascular permeability factor/endothelial growth factor (VPF/VEGF): accumulation and expression in human synovial fluids and rheumatoid synovial tissue. J Exp Med 1994;180:341-6.

14 Chu CQ, Field M, Abney E, Zheng RQ, Allard S, Feldmann M, et al. Transforming growth factor-beta 1 in rheumatoid synovial membrane and cartilage/pannus junction. Clin Exp Immunol 1991;86:380-6.

15 Goddard DH, Grossman SL, Williams WV, Weiner DB, Gross JL, Eidsvoog K, ef al. Regulation of synovial cell growth. Coexpression of transforming growth factor beta and basic fibroblast growth factor by cultured synovial cells. Arthritis Rheum 1992:35:1296-303.

16 Koch AE, Halloran MM, Hosaka S, Shah MR, Haskell CJ, Baker SK, et al. Hepatocyte growth factor. A cytokine mediating endothelial migration in inflammatory arthritis. Arthritis Rheum 1996;39:1566-75.

17 Nagashima M, Hasegawa J, Kato K, Yamazaki J, Nishigai K, Ishiwata $\mathrm{T}$, et al. Hepatocyte growth factor (HGF), HGF activator, and c-Met in synovial tissues in rheumatoid arthritis and osteoarthritis. J Rheumatol 2001;28:1772-8.

18 Gravallese EM, Manning C, Tsay A, Naito A, Pan C, Amento E, et al. Synovial tissue in rheumatoid arthritis is a source of osteoclast differentiation factor. Arthritis Rheum 2000;43:250-8.

19 Gravallese EM, Harada Y, Wang JT, Gorn AH, Thornhill TS, Goldring SR. Identification of cell types responsible for bone resorption in rheumatoid arthritis and juvenile rheumatoid arthritis. Am J Pathol 1998; 152:943-51

20 Scott BB, Zaratin PF, Colombo A, Hansbury M, Winkler JD, Jackson JR. Constitutive expression of angiopoietin-1 and -2 and modulation of their expression by inflammatory cytokines in rheumatoid arthritis synovial fibroblasts. J Rheumatol 2002;29:230-9.

21 Shahrara S, Volin MV, Connors MA, Haines GK, Koch AE. Differential expression of the angiogenic Tie receptor family in arthritic and normal synovial tissue. Arthritis Res 2002;4:201-8

22 Zimmermann T, Kunisch E, Pfeiffer R, Hirth A, Stahl HD, Sack U, et al. Isolation and characterization of rheumatoid arthritis synovial fibroblasts from primary culture-primary culture cells markedly differ from fourth-passage cells. Arthritis Res 2001;3:72-6.

23 Unemori EN, Hibbs MS, Amento EP. Constitutive expression of a 92-kD gelatinase (type $\mathrm{V}$ collagenase) by rheumatoid synovial fibroblasts and its induction in normal human fibroblasts by inflammatory cytokines. J Clin Invest 1991;88:1656-62.

24 Tsai C, Diaz LA Jr, Singer NG, Li LL, Kirsch AH, Mitra R, et al. Responsiveness of human $T$ lymphocytes to bacterial superantigens presented by cultured rheumatoid arthritis synoviocytes. Arthritis Rheum 1996;39:125-36.

25 Giatromanolaki A, Sivridis E, Brekken R, Thorpe PE, Anastasiadis P, Gatter KC, et al. The angiogenic "vascular endothelial growth factor/flk-1 (KDR) receptor" pathway in patients with endometrial carcinoma: prognostic and therapeutic implications. Cancer 2001;92:2569-77

26 Pufe T, Petersen W, Tillmann B, Mentlein R. The splice variants VEGF121 and VEGF189 of the angiogenic peptide vascular endothelial growth factor are expressed in osteoarthritic cartilage. Arthritis Rheum $2001 ; 44: 1082-8$ 
27 Witzenbichler B, Maisonpierre PC, Jones P, Yancopoulos GD, Isner JM Chemotactic properties of angiopoietin-1 and -2, ligands for the endothelial-specific receptor tyrosine kinase Tie2. J Biol Chem 1998;273:18514-21.

28 Fujikawa K, de Aos Scherpenseel I, Jain SK, Presman E, Varticovski L. Role of PI 3-kinase in angiopoietin-1-mediated migration and attachment-dependent survival of endothelial cells. Exp Cell Res 1999;253:663-72

29 Huang XL, Takakura N, Suda T. In vitro effects of angiopoietins and VEGF on hematopoietic and endothelial cells. Biochem Biophys Res Commun 1999;264:133-8.
30 Suri C, McClain J, Thurston G, McDonald DM, Zhou H, Oldmixon EH, et al. Increased vascularization in mice overexpressing angiopoietin-1. Science 1998;282:468-71.

31 Storgard CM, Stupack DG, Jonczyk A, Goodman SL, Fox RI, Cheresh DA. Decreased angiogenesis and arthritic disease in rabbits treated with an alphavbeta3 antagonist [see comments]. J Clin Invest 1999; 103:47-54

32 Miotla J, Maciewicz R, Kendrew J, Feldmann M, Paleolog E. Treatment with soluble VEGF receptor reduces disease severity in murine collagen-induced arthritis. Lab Invest 2000;80: 1 195-205.

ONLINE SUBMISSION.

New ARD online submission and review system

W

e are pleased to inform authors and reviewers of $A R D$ 's new online submission and review system: Bench Press. This is a fully integrated electronic system which uses the internet to allow rapid and efficient submission of manuscripts, and the entire peer review process to be conducted online.

Authors can submit their manuscript in any standard word processing software. Graphic formats acceptable are: .jpeg, .tiff, .gif, and .eps. Text and graphic files are automatically converted to PDF for ease of distribution and reviewing purposes. Authors are asked to approve their submission before it formally enters the reviewing process.

To access the system click on "SUBMITTING YOUR MANUSCRIPT" on the $A R D$ home page: http://www.annrheumdis.com/, or you can access Bench Press directly at http://submit-ard.bmjjournals.com/.

We are very excited with this new development and we would encourage authors and reviewers to use the online system where possible. It really is simple to use and should be a big improvement on the current peer review process. Full instructions can be found on Bench Press and ARD online.

Please contact Natalie Davies, Project Manager, ndavies@bmjgroup.com for further information.

\section{Pre-register with the system}

We would be grateful if all $A R D$ authors and reviewers pre-registered with the system. This will give you the opportunity to update your contact and expertise data, allowing us to provide you with a more efficient service.

\section{Instructions for registering}

1 Enter http://submit-ard.bmijournals.com

2 Click on "Create a new account" in the upper left hand side of the Bench Press home page

3 Enter your email address in the space provided

4 Choose a password for yourself and enter it in the spaces provided

5 Complete the question of your choice to be used in the event you cannot remember your password at a later time (this will be needed if you forget your password)

6 Click on the "Complete step 1" button at the bottom of the screen

7 Check the email account you registered under. An email will be sent to you with a verification number and URL.

8 Once you receive the email, copy the verification number and click on the URL hyperlink. Enter the verification number in the relevant field. Click on "Verify me". This is for security reasons and to check that your account is not being used fraudulently.

9 Enter/amend your contact information, and update your expertise data. 